\title{
É preciso voltar à fábrica e à produção
}

\section{Clarice Gontarski Speranza*}

REZENDE, Vinicius de. Vidas Fabris: Trabalho e conflito social no complexo coureirocalçadista de Franca-SP (1950-1980). São Paulo: Alameda, 2017.

Palavras-chave: trabalho; fábrica; Franca-SP.

Keywords: work; factory; Franca-SP.

Como já lembrado diversas vezes, a história dos trabalhadores brasileiros passou por intensa renovação desde as últimas décadas do século XX até hoje. Além da profunda transformação teórica que assentou a agência e a experiência junto ao conceito de classe, em detrimento de uma visão puramente estrutural, sem sujeitos - mudança influenciada pela crescente penetração e influência da obra de E. P. Thompson, entre outros autores -, novos temas, novas fontes e também o crescente número de pesquisadores tornaram esse campo historiográfico um dos mais férteis dos últimos tempos no país. A história dos trabalhadores deixou de ser focada exclusivamente ou prioritariamente no movimento sindical, descobrindo a cada nova pesquisa que, para além do sindicato, o trabalho também estava nas fábricas, nos bairros, nos espaços de lazer, dentro das casas. Além disso, o trabalho não era só masculino: tinha gênero, tinha raça, tinha etnia. Concepções construídas com base em modelos explicativos sociológicos foram confrontadas com as evidências empíricas, sendo repensadas pelos historiadores favorecidos por um campo documental também em expansão.

Um dos aspectos do alargamento desse campo específico de estudos históricos foram as pesquisas sobre o cotidiano fabril e o processo de trabalho, tendência verificada especialmente entre os anos 1980 e 1990. No entanto, aos poucos, a produção sobre as experiências fabris foi perdendo visibilidade, talvez pela emergência constante de temas ainda mais "novos" e instigantes. O que Vinícius de Rezende nos propõe em "Vidas Fabris: Trabalho e conflito social no complexo coureiro-calçadista de Franca-SP (1950-1980)" é justamente uma retomada à esfera da fábrica. Retorno, porém, renovado, no qual ferramentas e conceitos atuais da história econômica, da história social e da história cultural se conjugam para desvendar esse "mundo oculto" da produção por meio da análise qualificada de extensas e variadas fontes documentais.

A obra, originalmente a tese de doutorado do autor, defendida no Programa de Pós-Graduação em História Social da Universidade Estadual de Campinas (Unicamp) em 2012, enfoca o complexo coureiro-calçadista de Franca (SP), principal

* Professora do Departamento e do PPG em História da Universidade Federal do Rio Grande do Sul. 
produtor de calçados masculinos de couro no Brasil entre as décadas de 1950 e 1980. Rezende optou por privilegiar as experiências no "chão de fábrica", inserindo-as no processo de industrialização nacional, que traz em seu bojo a estruturação das relações capital-trabalho no país. Assim, alguns dos principais temas com os quais a historiografia do trabalho se defrontou nos últimos anos estão presentes ao longo das cerca de 500 páginas e seis capítulos do livro, trazidos a partir da perspectiva dos mecânicos, coureiros e sapateiros: a formação da mão de obra fabril, a migração rural, os conflitos com os gerentes, os atos de indisciplina e o absenteísmo, a luta por direitos legais, as greves e outras formas de resistência.

É difícil resumir a contribuição dada pela obra à historiografia do trabalho, dado justamente o amplo leque de objetos os quais se propõe a analisar. Impressiona o esforço de Rezende, por exemplo, em desvendar nos mínimos detalhes os diversos estágios da fabricação dos calçados em Franca, bem como a historicidade desta, desde a produção artesanal até tecnologias mais recentes. Logo no primeiro capítulo, o leitor é apresentado ao universo no qual o descarne e o curtimento (no caso dos couros), o corte, pesponto, colagem, ensacamento (no caso dos calçados propriamente ditos), bem como outras rotinas, são minuciosamente descritos, muitas vezes na voz dos próprios trabalhadores ou dos gerentes das fábricas.

Entre entrevistas feitas originalmente pelo autor e utilização de acervos de história oral, o estudo baseou-se em mais de 80 depoimentos agregados à ampla bibliografia, da qual constam inclusive manuais de produção. Tais fontes são empregadas para discutir, a partir de uma perspectiva empírica, o aumento da intensidade do trabalho a partir da incorporação das máquinas ao processo produtivo, resultando na crescente disciplinarização do trabalhador e perda de controle do tempo e do ritmo de trabalho - e como tais transformações eram vividas de fato por seres humanos reais.

A fase artesanal curta e restrita foi uma das razões pelas quais não se constituiu, entre os sapateiros de Franca, uma tradição de ofício capaz de estruturar ações e organização política - em contraste, por exemplo, com a experiência dos trabalhadores europeus do mesmo ofício. Isso, porém, não significou, demonstra o autor, que a categoria tenha se submetido resignadamente ao capital. Pelo contrário: as diversas manifestações conflituais, e em especial aquelas envolvendo o controle do ritmo e do tempo de trabalho, evidenciam uma construção de classe ativa e resistente. "O ideal taylorista de monopolização dos saberes operários pela gerência e pela 'ciência' sobre a melhor maneira de realizar um trabalho não se concretizou em todas as ocupações, se é que algum dia se concretizou plenamente em algum setor" (p. 164), observa Rezende.

Para compreender os conflitos entre chefes imediatos e operários no chão de fábrica, o autor utiliza o conceito de gestores formulado por João Bernardo. Esses são então compreendidos como uma segunda classe capitalista, ao lado da burguesia. Embora essa perspectiva não seja isenta de questionamentos, dada a própria ambiguidade dos sujeitos e especialmente pelo fato deles não deterem a propriedade dos meios de produção (entre outras questões), o conceito revela-se extremamente útil para a análise ao permitir enfocar separadamente esse grupo de indivíduos de importância vital para a produção e que, embora subordinados ao capital, dominam e controlam o processo produtivo na maioria das vezes com mais conhecimento do que a própria burguesia.

O controle do processo de trabalho é definido na obra como "a combinação de múltiplas ações e estratégias com o objetivo de transferir dos trabalhadores 
para os capitalistas as decisões a respeito da melhor maneira de executar um trabalho" (p. 227). A partir daí, a análise permite identificar na experiência dos trabalhadores das fábricas de calçados de Franca ao menos duas formas de controlar o processo de trabalho: uma baseada na empiria, na experiência de um ex-trabalhador transformado em gestor; e outra na autoridade proporcionada pelo conhecimento técnico-científico. Ambas demonstram maior ou menor efetividade (no sentido de eficiência produtiva) dependendo da situação, porém são incapazes de superar totalmente o conflito capital-trabalho.

Outro destaque do livro é a abordagem da resistência operária a partir de uma perspectiva inclusiva, que tenta compreender as diversas formas de ação dos trabalhadores como maneiras de se contrapor à dominação. Seguindo a formulação que "a resistência operária pode produzir uma transformação mais ampla do sistema de produção", Rezende enumera e analisa no rol dessas resistências desde as brincadeiras no chão de fábricas, o absenteísmo, a "cera", os acidentes e sabotagens, as agressões aos chefes, os roubos e furtos até as greves propriamente ditas. O resultado para o leitor é um passeio delicioso e instigante sobre formas culturais de reação à opressão do capital, desde as mais cotidianas e aparentemente "inocentes" até os enfrentamentos mais declarados. Somos assim apresentados às estratégias criativas de como burlar imposições, como o tempo limitado de ida ao banheiro, o estabelecimento de metas de produção, o ritmo estabelecido pelas máquinas; estratégias essas que incomodavam os capitalistas da mesma forma que as paralisações coletivas. Tal escolha teórica, além de enriquecer o relato, mostra a rejeição por uma visão teleológica (que atribui à classe tarefas e desígnios exteriores a ela), reiterando a valorização da agência do trabalhador.

Ao analisar as disputas no âmbito da Justiça do Trabalho, o estudo privilegia os dissídios individuais, ou seja, as ações trabalhistas de iniciativa de trabalhadores que, em sua maioria, giram em torno de questões aparentemente pontuais, como indisciplina e conflitos no chão de fábrica. Longe de considerar isso como demandas menores ou "querelas individuais", o autor lembra que tais reclamatórias refletem "questões coletivas, fosse pela recorrência do tema em centenas de processos ou por possuírem significados mais amplos no interior de uma empresa" (p. 404). Ao fazer isso, Rezende também se alinha a uma série de trabalhos recentes de história social que demonstram a potencialidade das fontes da Justiça do Trabalho, em especial aquelas produzidas sobre as reclamatórias de $1^{\text {a }}$ Instância, que, ao contrário dos dissídios coletivos, permitem observar o "trabalhador comum" em seus conflitos e demandas. Alguns temas merecem atenção especial: as disputas por garantias legais por parte dos trabalhadores a domicílio, a transformação do sentimento de gratidão do "aprendiz" em consciência de direitos, a busca da esfera judicial por trabalhadoras grávidas reivindicando estabilidade provisória, o recurso à Justiça do Trabalho para forçar o pagamento do adicional de insalubridade.

Como demonstram outras pesquisas de história do trabalho recentes, fica claro que, apesar da legislação trabalhista reconhecer o poder de comando das empresas sobre os trabalhadores, ela de fato restringia o que considerava "excessos", forçando não apenas o cumprimento das leis, mas também a limitação da ação disciplinar privada do capital. Vale destacar aí a abrangência das fontes judiciais utilizadas: a obra debruça-se sobre nada menos que 10.123 reclamações trabalhistas sob a guarda do Arquivo Histórico Municipal de Franca (a maioria delas, 52,5\%, resultando em conciliação, num percentual compatível com outros trabalhos que reafirmam a importância dos acordos no âmbito da Justiça do 
Trabalho). Desse universo total de ações judiciais, foram utilizados de forma mais intensa 1,4 mil processos, muitos deles com trechos reproduzidos nos capítulos.

Pela abrangência dos temas e fontes, pelas discussões teóricas que proporciona e por iluminar a experiência coletiva de uma porção extremamente relevante do operariado em um momento central para a industrialização nacional, Vidas Fabris é um lançamento importante e merece ser lido com atenção. Mais que isso: aponta para a necessidade de retomarmos o interesse pelo cotidiano da produção dentro das fábricas e para o manejo das ferramentas e conceitos da história econômica pelo historiador social. Se a identidade do trabalhador não se resume evidentemente à esfera da produção, é a partir da experiência primária na fábrica (e nos locais de trabalho em geral) que ele se constitui inicialmente como sujeito em oposição ao capital. Sem deixar de lado os outros temas desafiantes que cada vez mais surgem no fértil campo da história social do trabalho, Rezende nos alerta: precisamos voltar às fábricas.

Recebido em 02/04/2018

Aprovado em 03/04/2018 